\title{
Componentes da parede celular e digestibilidade in vitro de palha de arroz (Oryza sativa) com diferentes teores de silício ${ }^{1}$
}

\author{
Cell wall components and in vitro digestibility of rice (Oryza sativa) \\ straw with different silicon concentration
}

\author{
Leila Picolli da Silva ${ }^{2}$ Leandro Souza da Silva ${ }^{3}$ Humberto Bohnen ${ }^{4}$
} \begin{abstract}
O silício (Si) é absorvido pelas plantas e acumulado
na parte aérea, o que pode influenciar negativamente a qualidade
nutricional das forragens. O presente trabalho tem o objetivo de
avaliar o efeito do Si sobre a composição da parede celular,
estimada pelas análises de FDN, FDA e lignina, e sobre a
digestibilidade in vitro da parte aérea de plantas de arroz (Oryza
sativa) cultivadas em solução nutritiva sem e com adição de Si.
Houve diferença significativa nas quantidades de matéria
orgânica e cinzas totais entre os materiais e não houve diferença
significativa nos teores de parede total, celulose e lignina. Foi
encontrada maior quantidade de minerais associados à parede
celular na palha de arroz com adição de Si, que foi compensada
com a menor deposição da fração hemicelulose insolúvel em
FDN neste material. O Si não exerceu influência significativa na
digestibilidade in vitro da palha de arroz. RESUMO
\end{abstract}

Palavras-chave: sílica, celulose, hemicelulose, lignina.

\section{ABSTRACT}

Silicon (Si) is absorbed by plants and accumulated in shoot, what can affect nutritional quality of forages. The objective of this work was to evaluate the cell wall composition, estimated by FDA, FDN and lignin, and in vitro digestibility of rice shoots cultivated in nutritious solution with and without Si. There were differences in organic matter and ash contents, and there were no differences in total wall, cellulose and lignin. There were more minerals associated with cell wall of rice straw with $\mathrm{Si}$, which presented less hemi-cellulose deposition in this material. Silicon did not affect in vitro digestibility of rice straw.

Key words: silica, cellulose, hemi-cellulose, and lignin.

A qualidade das forragens como alimento está diretamente relacionada à sua composição nutricional, aliada a possíveis fatores antinutricionais, os quais geralmente estão envolvidos na proteção da planta contra a predação e biodegradação (VAN SOEST, 1981). Segundo o mesmo autor, o teor de lignina pode ser considerado como o principal fator da planta envolvido na redução da digestibilidade das forragens. Entretanto, o teor de sílica $\left(\mathrm{SiO}_{2}\right)$ poderia se tornar importante como limitante a digestibilidade, o que pode estar relacionado com o caso de palha de arroz (VAN SOEST \& JONES, 1968, VAN SOEST, 1981). JONES \& HANDRECK (1967) propõem o mecanismo da redução da digestibilidade propriamente dita, pois a sílica, assim como a lignina,

\footnotetext{
${ }^{1}$ Silva, beneficiário de auxílio financeiro do Programa de Apoio a Projetos Institucionais com a participação de Recém-Doutores da Coordenação de Aperfeiçoamento de Pessoal de Nível Superior (PRODOC/CAPES).

${ }^{2}$ Programa de Pós-graduação em Ciência e Tecnologia dos Alimentos, Centro de Ciências Rurais da Universidade Federal de Santa Maria (CCR/UFSM), Santa Maria, RS, Brasil.

${ }^{3}$ Departamento de Solos, CCR, UFSM, 97105-900, Santa Maria, RS, Brasil. E-mail: leandro@smail.ufsm.br. Autor para correspondência.

${ }^{4}$ Departamento de Solos, Faculdade de Agronomia, Universidade Federal do Rio Grande do Sul (UFRGS), Porto Alegre, RS, Brasil.
} 
faz parte da matriz da parede celular e ambas reduziriam a acessibilidade dos carboidratos da parede ao ataque dos microrganismos digestivos. Uma outra possibilidade, que não exclui a primeira, estaria relacionada com a menor palatabilidade do alimento para o animal, devido à presença de células altamente silificadas projetadas na borda das folhas, tornando o material áspero ao toque.

Não há um consenso na literatura a respeito do efeito do Si sobre a qualidade das forragens (VAN SOEST, 1994) devido ao fato que plantas com diferentes teores de sílica também apresentam diferentes teores de outros componentes importantes que afetam sobremaneira a digestibilidade, como os teores de lignina, arranjos diferenciados de fibrilas de celulose e a relação C/N. Assim, o ideal é avaliar o efeito do Si sobre a digestibilidade de plantas da mesma espécie, no mesmo estágio de desenvolvimento e com a mesma disponibilidade de nutrientes, mas com teores contrastantes deste elemento. O presente trabalho foi realizado com o objetivo de avaliar a hipótese do Si isoladamente afetar a qualidade da forragem, através da determinação da composição da fibra e da avaliação da digestibilidade in vitro em palha de arroz com diferentes teores do elemento, obtidas através do cultivo de plantas em solução nutritiva com e sem a adição do Si.

Para esse estudo, plântulas de arroz da cultivar BR-IRGA 410 foram cultivadas em vasos plásticos de $10 \mathrm{~L}$ contendo solução nutritiva completa, cujos teores de $\mathrm{SiO}_{2}$ no tecido foram de 0,2 e 3,2\%, respectivamente, obtidas e analisadas conforme descrito em SILVA \& BOHNEN (2001). Para análise da composição do tecido, amostras de cada tratamento foram moídas em moinho tipo "Wiley" com peneira de malha de $1 \mathrm{~mm}$ de diâmetro e determinados, em quatro repetições, os teores de matéria seca em estufa a $105^{\circ} \mathrm{C}$ (o qual foi utilizado para expressar os demais resultados), matéria orgânica (MO) e cinzas (Cz) após incineração das amostras em mufla a $550^{\circ} \mathrm{C}$ por quatro horas, de acordo com a metodologia descrita em AOAC (1980). As estimativas de parede celular total e de seus componentes foram obtidas pela análise de fibra em detergente neutro-FDN, fibra em detergente ácido-FDA (hemicelulose, celulose) e lignina bruta (lignina e minerais), conforme metodologias descritas em VAN SOEST \& WINE (1967). O teor de cada componente foi obtido da seguinte forma: fração solúvel $=100-\mathrm{FDN}$, parede celular $=$ FDN, hemicelulose $=$ FDN-FDA, celulose $=$ FDA-ligina bruta, lignina= lignina bruta-cinzas da lignina bruta.

A partir de uma amostra da palha moída $<1 \mathrm{~mm}$ e com tamanho de partícula entre 5 e $10 \mathrm{~mm}$, em 3 repetições, foi determinada a digestibilidade in vitro seguindo as metodologias descritas por JONES \& HAYWARD (1975) (incubação enzimática em dois estágios) e por TILLEY \& TERRY (1963) (digestão ruminal e ácida usando bovino da raça holandês como doador de inóculo). Os resultados obtidos em todos os parâmetros para as palhas sem e com adição de Si foram submetidos à análise de variância (teste $\mathrm{F}$, $\mathrm{P}<0,05)$.

Foram encontradas diferenças significativas $(\mathrm{P}<0,05)$ no teor de $\mathrm{MO}$ e $\mathrm{Cz}$ entre os dois materiais (Tabela 1 ), sendo que a absorção do Si pelas plantas que receberam adição do elemento aumentou a proporção de $\mathrm{Cz}$ e, conseqüentemente, diminuiu a proporção de MO do tecido, quando comparado com plantas sem adição de Si. Considerando a maior quantidade de $\mathrm{Cz}$ totais do tecido, as plantas que receberam adição de $\mathrm{Si}$ apresentaram, significativamente $(\mathrm{P}<0,05)$, maior quantidade de minerais associados à parede celular, em comparação com as plantas que não receberam o elemento (Tabela 1). Segundo VAN SOEST \& JONES (1968), apesar da cinza de FDA incluir outros minerais

Tabela 1 - Teores de matéria orgânica, cinzas, fração solúvel, componentes da parede celular e digestibilidade in vitro da palha de arroz cultivada em solução nutritiva com e sem adição de Si

\begin{tabular}{llcl}
\hline \multirow{2}{*}{ Parâmetro $^{1}$} & \multicolumn{3}{c}{ Palha } \\
\cline { 2 - 4 } & Sem silício & Com silício \\
\hline & $\%$
\end{tabular}

\begin{tabular}{lcc} 
Matéria Orgânica & $88,4 \mathrm{a}^{2}$ & $86,1 \mathrm{~b}$ \\
Cinzas & $11,6 \mathrm{~b}$ & $13,9 \mathrm{a}$ \\
& 30,5 & 32,8 \\
Fração Solúvel $^{3}$ & & \\
& & 67,2 \\
Parede Celular $^{4}$ & 69,5 & $24,6 \mathrm{~b}$ \\
Hemicelulose $^{5}$ & $28,9 \mathrm{a}$ & 35,6 \\
Celulose $^{6}$ & 37,1 & 3,8 \\
Lignina $^{7}$ & 3,4 & $3,1 \mathrm{a}$ \\
Minerais $^{8}$ & $0,1 \mathrm{~b}$ & \\
& & 40,1 \\
Digestibilidade & 39,2 & 65,4 \\
Celulase-pepsina & & \\
Tilley \& Terry & 66,3 & \\
\hline
\end{tabular}

${ }^{1}$ Base na matéria seca; ${ }^{2}$ letras distintas na linha indicam diferença significativa de acordo F-teste $(\mathrm{P}<0,05)$; ${ }^{3}$ fração solúvel $=100$ FDN; ${ }^{4} \mathrm{FDN} ;{ }^{5}$ hemicelulose $=$ FDN-FDA; ${ }^{6}$ celulose $=$ FDA-ligina bruta; ${ }^{7}$ lignina $=$ lignina bruta-cinzas da lignina bruta; $e^{8}$ cinzas da lignina bruta.

Ciência Rural, v. 35, n. 5, set-out, 2005. 
indigestíveis, esta pode ser considerada um índice satisfatório para avaliação do teor de sílica na planta. A proporção total de parede celular não foi diferente entre os materiais $(\mathrm{P}>0,05)$, sendo a maior quantidade de minerais da parede celular nas plantas com adição de $\mathrm{Si}$, compensada pela menor quantidade de hemicelulose, tendo em vista que os teores de lignina e celulose também não foram significativamente diferentes ( $\mathrm{P}>0,05)$ (Tabela 1). MINSON (1971), estudando o efeito do Si na digestibilidade, levanta a possibilidade de que este possa provocar mudanças nos teores de lignina, provavelmente devido ao papel semelhante de ambos em fortalecer e proporcionar rigidez a parede celular (VAN SOEST, 1994) e o baixo custo energético para a planta incorporar $\mathrm{Si}$, em relação à lignina (LIMA FILHO et al., 1999). Entretanto, a influência do Si sobre os teores de hemicelulose sugere efeitos deste elemento sobre o metabolismo de formação da parede celular das plantas.

Apesar das variações na composição, não foram encontradas diferenças significativas na digestibilidade in vitro da palha do arroz cultivado com e sem a adição do elemento ( $\mathrm{P}>0,05)$ (Tabela 1$)$. Dessa forma, pode-se inferir que o Si absorvido e depositado na parede celular da parte aérea de plantas de arroz não alterou a acessibilidade das enzimas ao material celular. Alguns dos trabalhos que encontraram efeito de Si na digestibilidade de forragens (VAN SOEST, 1968; SMITH et al., 1971) utilizaram a correlação entre a diferença matemática da digestibilidade estimada e a real, considerando espécies vegetais com diferentes teores de Si. No entanto, MINSON (1971), semelhante ao presente trabalho, não encontrou efeito do Si sobre a digestibilidade $(\mathrm{P}>0,05)$, questionando a metodologia anterior como sendo apenas um efeito de cálculo, uma vez que não foi feita a correção dos valores de digestibilidade para o teor de cinzas.

Em outros casos, o efeito do Si foi obtido com a adição de doses de silicato de sódio na cultura ruminal, que pode causar efeitos sobre disponibilidade de outros nutrientes e, conseqüentemente, alterar a digestibilidade do material (SMITH \& NELSON, 1975). Já a relação obtida por VAN SOEST (1981), entre a remoção de Si do material naturalmente silificado com detergente neutro e o aumento da digestibilidade in vitro, pode ser resultante de um efeito adicional do tratamento, a qual enfraquecia as ligações entre os carboidratos estruturais.

Embora não evidenciado efeito na digestibilidade in vitro neste trabalho, o $\mathrm{Si}$, juntamente com a camada de cutina, ainda pode apresentar-se como uma barreira à colonização das bactérias ruminais, alterando a digestibilidade do material in vivo (BAE et al, 1997). Além disso, as forragens com altos teores de Si são mais abrasivas, o que pode afetar a seleção e palatabilidade dos animais (VAN SOEST, 1994).

\section{CONCLUSÃO}

A adição de Si proporcionou maior quantidade de minerais associados à parede celular na palha de arroz, que foi compensada com a menor deposição da fração hemicelulose insolúvel em FDN neste material, mas não exerceu influência significativa na digestibilidade in vitro da palha.

\section{REFERÊNCIAS}

ASSOCIATION OF OFFICIAL ANALYTICAL CHEMISTS AOAC. Official methods of analysis. 13.ed. Washington: AOAC, 1980. 1015p.

BAE, H.D. et al. Effect of silica on the colonization of rice straw by ruminal bacteria. Animal Feed Science and Technology, Amsterdan, v.65, n.1-4, p.165-181, 1997.

JONES, D.I.H.; HAYWARD, M.V. The effect of pepsin pretreatment of herbage on the prediction of dry matter digestibility for solubility in fungal cellulose solution. Journal of the Science of Food and Agriculture, London, v.26, n.3, p.711-718, 1975.

JONES, L.H.P.; HANDRECK, K.A. Silica in soils, plants, and animals. Advances in Agronomy, New York, v.19, p.107149, 1967.

LIMA FILHO, O.F. et al. O silício na agricultura. Informações Agronômicas, Piracicaba, n.87, p. 1-7, 1999.

MINSON, D.J. Influence of lignin and silicon on a summative system for assessing the organic matter digestibility of Panicum. Australian Journal of Agricultural Research, East Melbourne, v.22, n.4, p.589-598, 1971.

SILVA, L.S.; BOHNEN, H. Rendimento e acúmulo de nutrientes pelo arroz (Oryza sativa) em solução nutritiva com e sem a adição de silício. Revista Brasileira de Ciência do Solo, Viçosa, v.25, n.3, p.771-777, 2001.

SMITH, G.S. et al. Digestibility of forages in vitro as affected by content of “silica”. Journal of Animal Science, Savoy, v.33, p.466-471, 1971.

SMITH, G.S.; NELSON, A.B. Effects of sodium silicate added to rumen cultures on forage digestion, with interactions of glucose, urea and minerals. Journal of Animal Science, Savoy, v.41, p.891-899, 1975.

TILLEY, J.M.A.; TERRY, R.A. A two-stage technique for the in vitro digestion of forage crops. Journal of British Society, v.18, p.104-111, 1963. 
VAN SOEST, P.J. Limiting factors in plant residues of low biodegradability. Agricultural and Environmental, Amsterdam, v.6, p.135-143, 1981 .

VAN SOEST, P.J. Nutritional ecology of the ruminant. 2.ed. Ithaca : Cornel University, 1994. 476p.
VAN SOEST, P.J.; JONES, L.H. Effect of silica in forages upon digestibility. Journal of Dairy Science, v.51, p.1644-1648, 1968.

VAN SOEST, P.J.; WINE, R.H. Use of detergents in the analysis of fibrous feeds. IV. Determination of plant-cell constituents. Journal of the Association of Official Analytical Chemists, v.50, p.50-55, 1967. 